\title{
Innovative qualification network in the field of optical technologies realised in the course of studies Laser and Optotechnologies
}

Jens Bliedtner, Yvonne Weigel

Jens Bliedtner, Yvonne Weigel, "Innovative qualification network in the field of optical technologies realised in the course of studies Laser and Optotechnologies," Proc. SPIE 9664, Ninth International Topical Meeting on Education and Training in Optics and Photonics, 966414 (24 October 2005); doi: $10.1117 / 12.2207737$

Event: Ninth International Topical Meeting on Education and Training in Optics and Photonics, 2005, Marseille, France 


\title{
Ref ETOP071
}

\section{Innovative qualification network in the field of optical technologies realised in the course of studies Laser and Optotechnologies}

\author{
Jens Bliedtner \& Yvonne Weigel
}

\begin{abstract}
Realising the manifold innovations and research results in the field of optical technologies requires a more intense and target-oriented qualification of the students in the next years. In a model project a qualification network between the university, enterprises and research institutions was established for a new consecutive course of studies "Laser and Optotechnologies" at the University of Applied Sciences Jena. The integration of experts from industry and research as well as the introduction of new education methods enables a more practice and science-oriented qualification, enhancing the qualification level and the students' chances on the job market at the same time.
\end{abstract}

\section{Summary}

At present there is a great discrepancy between the number of available specialists and the demand for technical engineers in the field of optical technologies. In order to realise the large number of present and future developments in this field well-trained specialists will be needed in the next years. The high standards of qualification are not only important for graduates from university but for specialists working in various companies of the optical industry as well. A survey, carried out by the competence network OptoNet Thüringen e.V., reflects this statement having detected a demand for qualification of $55.6 \%$ among the emnlovees in the investiaated comnanies

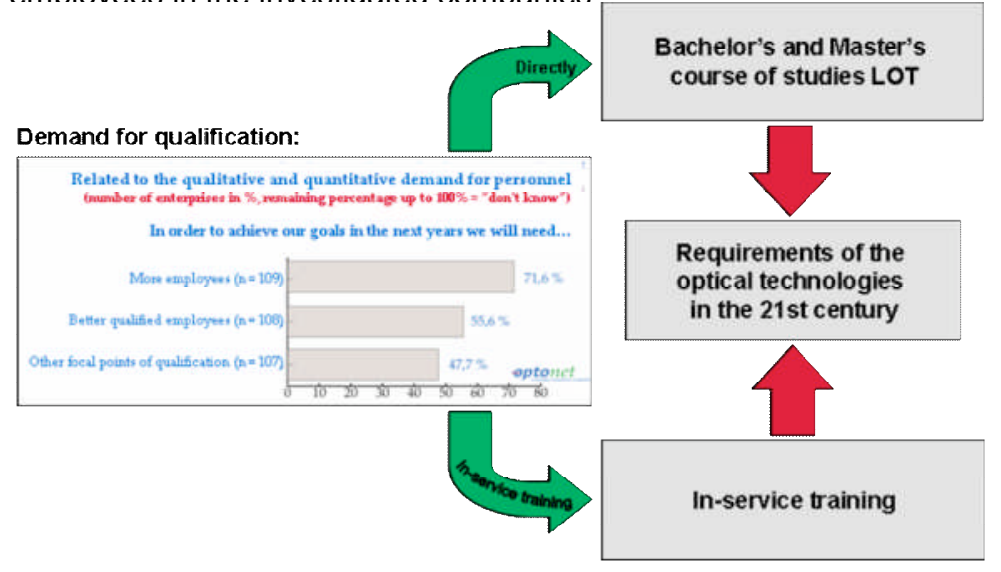

Figure 1: Demand for qualification in the optical industry of Thuringia

The direct as well as the indirect way of education are essential for achieving the required qualification level. A qualification network model between the university, various research institutes and industrial enterprises was established in order to minimise the abovementioned deficit and to realise modern educational concepts. This model mainly aims at including the latest research results of the institutes and enterprises into the education of students who want to obtain a Master's degree in the field of optical technologies. Especially by co-operating with enterprises of the optical industry the education of the students can be flexibly adjusted to their needs. The course "Laser and Optotechnologies" LOT is a 
consecutive course of studies in the direct way of education with a duration of 6 plus 4 semesters. As regards content the main focus is in the field of laser technology, optical technology, optical development and optoelectronics. Specialisation in different occupational fields is a crucial instrument for practice-oriented education. This additional form of Master studies enables the students to obtain special knowledge for a smooth and quick integration into company operation after having successfully graduated. Master students are qualified e.g. for laser beam specialists or optical designers.

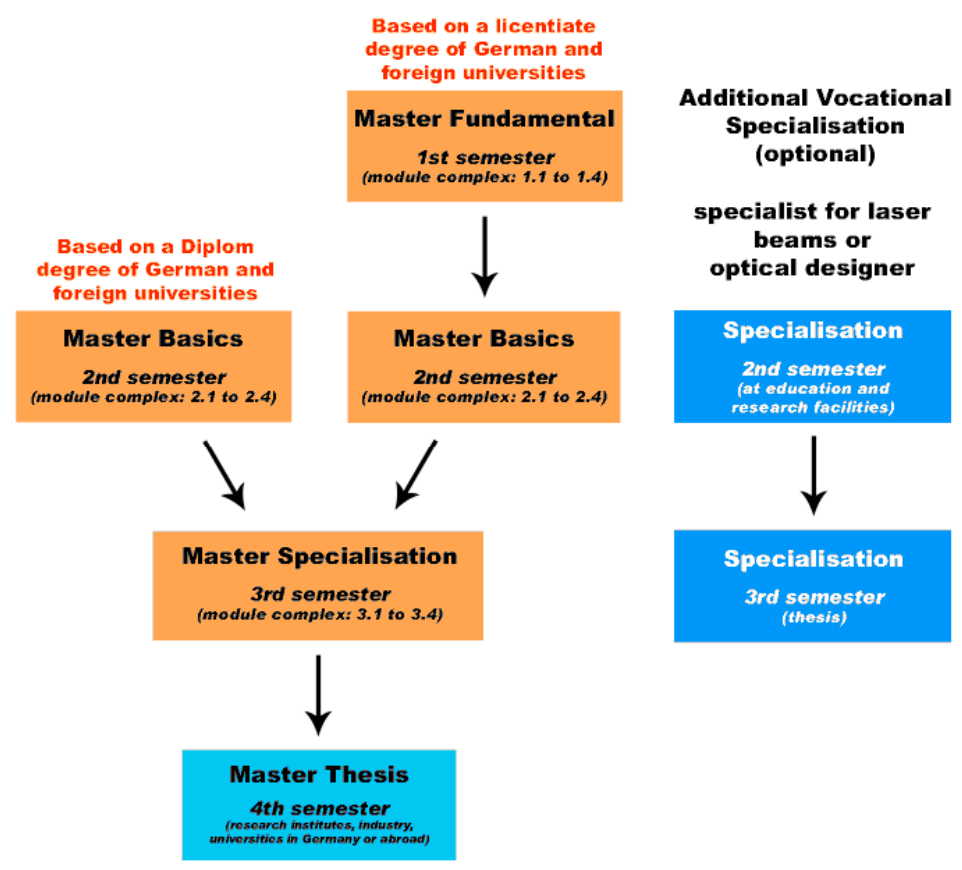

Figure 2: Organigram of the Master's course of studies LOT

The integration of experts from industry and research institutes into university education enables an extended range of topics from research and development in lectures, for projects, internships, Bachelor and Master Theses. At the same time it facilitates a smooth transition of students from university into industrial enterprises.

The indirect way of education is used by companies within the competence network OptoNet Thüringen e.V. They utilise the existing education structure at the University of Applied Sciences Jena in the field of optical technologies for in-service training of their employees.

Topics such as technical optics, laser technologies, laser measuring technologies or optical technologies are offered in modules for beginners and advanced students. The qualification needs in the indirect way of education provide feedback for future topics of qualification in the direct way of education.

The qualification network can react very well to the industrial utilisation of innovative products and procedures of the branch and flexibly educate students. The tight connections to optical enterprises guarantee a practice-oriented education and simultaneously increase the chances for graduates.

The project was supported by the Federal Ministry for Education and Research Germany and the Thuringian Ministry of Education. 